\title{
A Tutela Jurisdicional na Transmissão Post Mortem de Bens Digitais
}

\section{The Legal Protection in the Post Mortem Transmission of Digital Goods}

\author{
Michele Gonçalves ${ }^{\mathrm{a}}$; Iracema Fazio*b
}

${ }^{a}$ UNIME, Curso de Direito. BA, Brasil.

${ }^{\mathrm{b}}$ UNIME Lauro de Freitas, Coordenação Acadêmica. BA, Brasil.

*E-mail: iracema.fazio@hotmail.com.

\begin{abstract}
Resumo
A era digital é uma verdadeira revolução no acesso à informação e toda essa transformação vem influenciando o modo como as pessoas estão se comunicando e interagindo entre elas. Devido a esse avanço tecnológico o acervo digital passa a ser relevante no âmbito jurídico sendo reconhecido como um bem de valor econômico e sentimental. A herança digital é uma realidade e o Direito precisa avançar lado a lado para alcançar as grandes mudanças trazidas no meio social, implicando em definir o que será feito com o acervo digital após a morte do titular de contas em plataformas digitais de comunicação e interação social. Logo, não se tem uma lei específica que trate desse assunto. Destarte, o presente trabalho teve o objetivo de analisar a destinação dos bens digitais quando o titular não declara em vida a sua vontade. Enfim, foi analisado o tradicional instituto sucessão, confrontando-se a sua adequação à transmissão de bens digitais após a morte quando não existir testamento, ensejando assim a sua total proteção.
\end{abstract}

Palavras-chave: Bens Digitais. Transmissão Mortis Causa. Legado Digital. Herança Digital.

\begin{abstract}
The digital age is a real revolution in the access to information and all this transformation has been influencing the way people are communicating and interacting with each other. Due to this technological advancement, the digital collection becomes relevant in the legal sphere, being recognized as a good of economic and sentimental value. The digital inheritance is a reality and the Law needs to advance side by side to achieve the great changes brought about in the social environment, implying in defining what will be done with the digital collection after the death of the account holder in digital communication and social interaction platforms. Therefore, there is no specific law dealing with this matter. Thus, the present study aimed to analyze the destination of digital goods when the holder does not declare his will alive. Finally, the traditional succession institute was analyzed, comparing its adequacy to the transmission of digital goods after death when there is no will, thus giving rise to its total protection.
\end{abstract}

Keywords: Digital Goods. Mortis Cause Transmission. Digital Legacy. Digital Inheritance.

\section{Introdução}

O presente trabalho vai estudar o conceito de herança digital ainda pouco conhecido, preocupando-se em difundir a noção de acervo digital com valor patrimonial e jurídico, tais como, fotos e vídeos em formato digital, contas em redes sociais (Twitter, Facebook, Snapchat, WhatsApp, Instagram e Pinterest) senhas, assinaturas digitais, histórico de bate papo, softwares, aplicativos, jogos e cursos online.

Deste modo, em tempos de sociedade da informação conectada e digital é importante o debate jurídico sobre a administração do acervo digital do falecido, especialmente a fim de definir-se de que forma será realizada a transmissão dos bens que integram este acervo aos sucessores do mesmo. Ou seja, entender se é possível a adoção de algum instrumento jurídico que tutele a declaração de última vontade do falecido sobre a transferência do acervo digital por este deixado.

Sem embargo esta discussão passa por inicialmente compreender o que são os bens digitais, estabelecer qual o marco regulatório que os definem e protegem e, em seguida determinar a aplicação do regime sucessório adequado para os mesmos.

Notadamente, o direito ainda engatinha sobre o tema, restando aos operadores do direito lidar com a matéria de forma interpretativa, valendo-se quer de direitos e garantias fundamentais, constitucionalmente ancorados, quer do Marco Civil da Internet.

Obviamente que esta análise deve ser realizada à luz do que tecnologicamente encontra-se disponível a fim de garantir a proteção destes direitos fundamentais, ou seja, do direito à sucessão aberta dos herdeiros sob o patrimônio digital deixado pelo falecido, como pelo direito deste à declaração de última vontade.

Deste modo, a presente investigação não se restringirá a análise da legislação existente, como também dos projetos de lei que tramitam no legislativo sobre a matéria, como também pelo estudo dos Termos e Políticas de Serviços disponibilizados pelos provedores de aplicação da internet, responsáveis pelas plataformas comunicação e interação social.

Observe-se que este trabalho preocupar-se-á em realizar à análise do tema à luz do avanço tecnológico já presente que 
impactou de sobremaneira a vida das pessoas. Assim, pretendese demonstrar que o direito precisa evoluir, adequando-se à esta nova realidade digital de interações sociais, estabelecendo um marco regulatório adequado à tutela dos bens que compõem o acervo digital do falecido.

$\mathrm{Na}$ verdade, este trabalho irá debruçar-se sobre a necessidade do direito ampliar a noção de patrimônio, compreendendo que os bens desmaterializados assumiram valoração econômica e pessoal de grande relevo na composição do patrimônio dos sujeitos de direitos e deveres.

Sem embargo, avance-se que grande parte dos bens que compõe o acervo digital do falecido assumem natureza exponencialmente sentimental e ao mesmo tempo patrimonial, que merecem tratamento diferenciado, especialmente pelo avançado risco de perecimento.

Neste sentido, o presente trabalho preocupar-se-á em discutir de que modo o direito pode conferir tutela aos bens digitais construídos e acumulados em vida pelo falecido, bem como, o modo mais adequado para garantir a transferência dos mesmos após a morte deste.

Outrossim, este trabalho avança no estudo do tema, pois que irá discutir de que modo se pode tutelar os bens que compõe o acervo digital do falecido, na hipótese de ausência de declaração de última vontade deste, quer por este desconhecer esta possibilidade, quer por tecnologicamente não se fornecer instrumentos para tanto.

Cumpre-se informar que o objetivo geral deste trabalho é compreender o que se entende por herança digital, isto é, entender de que modo se dá a sucessão dos bens que compõe o acervo digital do falecido. Para o que se levantou os seguintes objetivos específicos: compreender a necessidade de tutela jurídica adequada aos bens digitais; discutir a transmissão dos bens digitais do falecido; confrontar e interpretar a legislação existente aplicável ao tema; analisar os termos e políticas de serviços das plataformas de comunicação e interação social; estudar os projetos de lei que pretendem regulamentar especialmente a transmissão desses bens digitais.

Muito embora, o presente trabalho não deve ser entendido como exauriente sobre o tema, já que levanta algumas dúvidas a serem respondidas em pesquisa futura, registre-se que ao final apresenta solução temporária, à espera de melhor enquadramento jurídico sobre a matéria.

\section{Desenvolvimento}

\subsection{Metodologia}

Este trabalho adota qualifica-se por uma pesquisa bibliográfica da espécia qualitativa, que se preocupou em realizar a adequada revisão de literatura, utilizando doutrinadores tradicionais e específicos sobre o tema. Além disso, realizou pesquisa jurisprudencial sobre os poucos casos trazidos à análise ao judiciário brasileiro.

O presente trabalho está dividido em três seções, e mais em introdução e em considerações conclusivas. Na primeira seção estuda-se a noção de bens digitais e a sua tutela jurídica, na segunda seção estuda-se a sucessão dos bens que compõem o acervo digital do falecido e na terceira seção estuda-se alguns projetos de lei que pretendem regular o tema de modo especial.

\subsection{Bens Jurídicos}

É possível afirmar que bens são coisas com interesse econômico e/ou jurídico, ou seja, são aqueles suscetíveis de relevância no mundo jurídico. Podendo assim adequar-se na relação jurídica trazendo em seu objeto um bem jurídico.

O código civil utiliza somente a expressão bens, mas é de grande relevância entender que nem todas as coisas são bens. Logo, nem todas as coisas importam ao direito, uma vez que a criatura só usurpa das coisas primordiais quando lhe agrada em suas conveniências. De modo que o homem procura por uma coisa interminável ou excessivamente produtiva, destinando assim ao uso da comunidade, ou seja, ao uso comum destinado a todos, como água, ar atmosférico, porém, não há motivo para que esse tipo de bem seja regulado pelo ordenamento jurídico, porque não existe nenhuma relevância econômica em controlá-lo. (VENOSA:2003)

Nessa linha de ideias, percebida a existência de determinados objetos de relações jurídicas sem expressão econômica, a noção de esfera jurídica de interesse transcende a economicidade e a materialidade dos bens jurídicos, sendo induvidosa a existência de relações jurídicas, protegidas pelo ordenamento jurídico, cujo objeto não reflete valor econômico ou mesmo cujo objeto, apesar de possuir valor econômico, não admite apropriação material.

De acordo com Silvio Rodrigues (2002) coisa é gênero, e bem seria espécie: Coisa é tudo que existe objetivamente, com exclusão do homem. Os bens são coisas que, por serem úteis e raras, são suscetíveis de apropriação e contem valor econômico. (RODRIGUES, 2002 apud FARIAS, 2015, p.421).

Logo, só serão incorporados ao patrimônio da pessoa física ou jurídica as coisas essenciais e singulares que provocam concorrência entre as pessoas, dando, a elas essa adequação, princípio ao um ligame jurídico que é o domínio.

A classificação dos bens acrescenta como objetivo auxiliar na compreensão do instituto aglomerado de várias e diferentes espécies. Há de identificar evidente relevância na utilização das classificações dos bens, em razão da necessária identificação das disposições que deverão reger as relações negociais patrimoniais e a própria tutela de cada uma das categorias de bens jurídicos.

Malgrado, não esteja presente no código civil de 2002 a classificação dos bens em corpóreos e incorpóreos é de suma importância entendê-lo para melhor proteção desses bens. Entender as especificações desses bens, para que dessa forma as pessoas possam reconhecer que eles existem e que podem compor o seu acervo. 
O próprio Código Civil Brasileiro não adotou nenhuma corrente doutrinária que tenta diferenciar bens e coisas, tanto que em sua parte geral existe um livro que trata dos bens; e depois em sua parte especial o código traz outro livro que trata do direito das coisas; ele trata conjuntamente a expressão bem e coisa, considerando-as como se fossem sinônimas.

É notório, a grande divergência entre os civilistas, no que tange sobre a definição do que venha ser o bem jurídico. Tartuce ensina que os "bens corpóreos, materiais ou tangíveis - são aqueles bens que possuem existência corpórea, podendo ser tocadas". (TARTUCE, 2017, p. 200

Para Cristiano Chaves e Nelson Rosenvald (2015), corpóreos são bens que tem existência material, perceptível pelos sentidos humanos, como uma casa, um livro, um relógio. Já os bens incorpóreos não têm existência materializável, sendo abstratos, de visualização ideal, como exemplo o direito autoral. (DINIZ, 2011)

A classificação desses bens materiais para esses autores são aqueles bens palpáveis que se pode tocar, ou seja, pode ser visualizado no mundo material. Já os imateriais são aqueles bens que não se pode apalpar, mas sabe-se que eles existem, não sendo possível pegá-lo, ou seja, no material não é possível enxergá-lo, sabendo-se que eles têm grande relevância no âmbito jurídico e por isso merece ser protegido pelo Direito.

Convém esclarecer, contudo, que não é, neste caso, o homem objeto do direito, mas a prestação como resultado da atividade humana. Assim, o patrimônio é o complexo de relações jurídicas de uma pessoa, apreciáveis economicamente.

Dessa maneira, é possível encontrar no objeto das relações jurídicas subjetivas, além dos bens jurídicos economicamente apreciáveis, os atributos ou manifestações da personalidade do próprio sujeito (direitos da personalidade) e as atividades e serviços de natureza técnica (propriedade intelectual).

$\mathrm{O}$ conceito de bens e coisas, sempre trouxe divergências na doutrina Brasileira. Juridicamente, bens seriam aqueles valores materiais ou imateriais que podem servir de objeto de uma relação jurídica. (BEVILÁQUIA, 2001)

Seriam esses bens, não econômicos, prolongamentos ou emanações da personalidade, como, por exemplo, a vida, a liberdade, o nome, a honra etc. É imperioso atentar-se para a definição clássica de bem, que irá direcionar para o conceito mais adequado para assim alcançar definição dos bens digitais. (AMARAL, 2008)

Aliás, na contemporaneidade é exigida uma nova compreensão dos bens e, consequentemente, da propriedade, em razão dos processos econômicos, das novas descobertas científicas e da acomodação das necessidades sociais.

Sem dúvida, portanto, é possível perceber novos surgimentos na teoria dos bens, consequência da evolução tecnológica, em que estão transformando a sociedade, demonstrando grande interesse jurídico, exemplos no programa de computadores, no software, no know-how, entre outros, que possuem grande relevância nas relações jurídicas.

O Brasil vem encaminhado para o common law, em que, o direito não consegue avançar juntamente com as mudanças sociais. Ainda que o ordenamento jurídico não consiga andar junto com as mudanças sociais, ele deve ao menos tentar evoluir e não se tornar tão obsoleto. É perceptível que muitas decisões da suprema corte, não estão pautadas na literalidade da lei, ou seja, tem se dado uma nova interpretação (Mutação Constitucional) a luz da constituição expandindo assim e alcançando novos direitos. Devido ao processo legislativo ser tão rigoroso, características da constituição originária em seu aspecto rígido, ou melhor, as leis criadas ou em formação vêm sendo esparsas em seu conteúdo, e muitas delas quando entram em vigor já perdeu a essência em resolver os determinados conflitos. Por esse modo, a ausência de legislação, não significa ausência de direito.

Para o código civil somente os bens economicamente apreciáveis podem ser objeto de relações jurídicas, portanto fica claro que compõem o acervo do falecido e devem constar na sucessão, por assim entender boa parte doutrinária. É mister a necessidade de se interpretar a extensão da valorização de determinados bens classificados pelo legislador como bens econômicos, pois o que não se considera hoje como bens valoráveis, amanhã poderá ser.

Com a atual mudança advinda das novas figuras na teoria dos bens em razão das descobertas cientificas e das necessidades sociais, sustentando alto significado no meio ambiente, nos programas de computadores, dentre outros podendo ser objeto das relações jurídicas, em razão das descobertas cientificas e das necessidades sociais é preciso compreender os novos conceitos de bens.

$\mathrm{O}$ avolumamento na internet ensejou interesse no ambiente virtual, devido a sua celeridade nas informações compartilhadas. Com isso as relações sociais vêm sendo desenvolvida em sua grande maioria através do espaço virtual, ou seja, as pessoas se comunicam pela rede sociais.

É cediço que maior parte das pessoas utilizam contas de e-mail ou em alguma rede social. Logo, boa parte dos bens que antigamente eram acomodados em meios físicos são armazenados em meio digital, quer dizer, passa-se de um mundo físico para um mundo digital.

Como exemplo, as fotos, vídeos, músicas, livros, documentos, escritos, mensagens, entre outros. Desta feita, os dados que podem revelar aspectos da privacidade de um indivíduo ficam resguardados sob sigilo, em que se encontram assegurados pela carta magna como direitos e garantias individuais, esculpido no art. $5^{\circ}$, inciso XII, a esses dados serão chamados de dados sensíveis, por entender que esse direito será titularizado pelo sujeito individualmente, razão pela qual, se estará no campo do Direito Privado. É certo quanto aos dados não sensíveis, não estão protegidos pelo sigilo, pois são informações públicas e de livre circulação por terceiros. Para exemplificar, o nome das pessoas, estado civil, filiação, o número do CPF, o endereço ou e-mail.

Logo, a internet conhecida como uma rede sem fronteiras, em que as pessoas externalizam seus pensamentos, ou melhor, 
muitas das vezes expõem suas ideais sem respeitar a pessoa que se encontra do outro lado, achando assim que o mundo virtual é terra sem lei. Atualmente pode notar que isso mudou, a pessoa já vem se comportando de forma diversa, devido ao aparato legislativo vigente, afim de que, se possa ter um controle no mundo virtual, com um propósito de impor aos seus usuários determinados limites no sentido do seu uso.

Partindo da premissa do conceito de bens será assim comparado quanto aos bens digitais, podendo ser qualquer coisa possuída em meio digital. Podem ser classificados como coisas armazenadas localmente em um dispositivo eletrônico ou coisas que são armazenadas em outros locais na (nuvem), acessados através de contrato.

Em determinadas circunstâncias, um arquivo digital, pode não ter alcançado um custo econômico capaz de ser considerado importante para compor os bens, nada obstante no amanhã o reconheça, como acontece com artigos antigos e raros que passam a ter valor não pelo produto, mas sim pela história que carrega.

É de suma importância entender o conceito de bens digitais, com a finalidade de a partir daí possa ter uma fácil identificação e, deste modo possa ocorrer arrecadação dos bens do de cujus. (EMERENCIANO, 2003 apud LARA, 2016)

Pois na maioria das vezes o dono desse acervo não consegue exprimir a sua vontade, por não saber que esses bens imateriais poderão compor o seu conjunto de bens, visto que muitos deles não conhecem da possibilidade de estarem manifestando sua vontade em face desses bens incorpóreos.

Entende-se por bens digitais toda aquela informação que são inseridas na web armazenada na rede e tem as expectativas de ser proprietário ou ter o seu controle, bem como, Correio eletrônico (fotos, músicas, vídeos, jogos online, livros, bitcoin), impactando dois fenômenos econômico ou sentimental. Tudo que consegue ser armazenado no mundo digital é um bem digital é um acervo que tem valor sentimental e econômico.

Sendo assim, bens digitais são instruções traduzidas em linguagem dos computadores, ou seja, linguagem binária que são dados armazenados no computador com uma sequência de códigos que podem ser processadas em dispositivos eletrônicos, quaisquer informações que podem ser armazenadas nos diversos aparelhos como computadores, celulares e tablets.

Logo não há empecilho em considerar patrimônio alguns tipos de arquivos digitais (filmes, blogs, páginas na internet, músicas, livros etc.), pois é possível verificar a existência de relações jurídicas "dotadas de valor econômico".

Além dos bens de cunho patrimonial, existe aquele de caráter pessoal, muitas vezes sentimental, alguma foto e/ou documento da família, um e-mail e outros arquivos que podem se perder, caso não seja realizada a herança digital de maneira efetiva, gerando um grande aborrecimento nos familiares.

Bens digitais de natureza existências (sensíveis/ personalíssimo) compõem a identidade pessoal do usuário intimidade e privacidade ex. WhatsApp. São direitos assegurados na carta magna, que não deve ser violado, a não ser que exista uma permissão por parte do de cujus. Pode haver conflito entre esses bens, assim será necessário, fazer a ponderação.

Alguns direitos da personalidade se protraem após a morte, a pessoa em vida poderá autorizar, isto é, poderá fazer uma declaração pública que irá gerenciar todo o seu acervo digital.

\subsection{A Sucessão dos Bens Jurídicos Digitais}

A morte é um tema bastante delicado, por isso, em geral há grande dificuldade de se tratar sobre o mesmo. No entanto, a morte é certa, faz parte da vida.

Como sabido, o evento morte enseja reflexo no mundo jurídico, caracterizando-se como fato jurídico que conduz à sucessão. Opera-se, assim, através da sucessão, a troca de titulares de um direito, afastando-se uma pessoa da relação jurídica e, em seu lugar, ingressando outra, que assume todas as obrigações e direitos de seu antecessor. (DINIZ, 2014)

A palavra sucessão, em seu sentido mais amplo, designa o ato pelo qual uma pessoa se coloca no lugar da outra, sendo substituída na titularidade de determinados bens.

Destaque-se, que o Direito das Sucessões tem como objetivo a mudança da titularidade de um determinado bem de uma pessoa para outra em decorrência da morte, isto é, trata-se aqui da sucessão causa mortis.

Para Giselda Hironaka (2007) o direito hereditário, apresenta-se como o conjunto de regras e complexo de princípios jurídicos pertinentes à passagem da titularidade do patrimônio de alguém que deixa de existir aos seus sucessores.

O Direito das Sucessões é o ramo do Direito que existe devido à morte, que é à necessidade de manutenção da propriedade privada para a preservação da família. (STOLZE; PABLO; PAMPLONA, 2015)

Venosa (2007, p. 20) destaca sobre o Direito Sucessório que: "A ideia de sucessão por causa da morte não aflora unicamente no interesse privado: o Estado também tem o maior interesse de que um patrimônio não reste sem titular, o que lhe traria um ônus a mais".

Anote-se ainda que o direito à sucessão se trata duma garantia fundamental, pois protege a família, visto que, as pessoas que dependiam do falecido para sobreviver poderão se manter através da administração desses bens.

$\mathrm{O}$ direito à sucessão aberta encontra-se consagrado constitucionalmente e, por corolário, possui status de direito fundamental mediante o disposto no artigo $5^{\circ}$, inciso XXX, que dispõe: É garantido o direito de herança. Ao incluir a herança entre os direitos fundamentais, a Constituição Federal garantiu proteção ao instituto (SARLET, 2009).

Observa-se que a herança, como direito concede ao cidadão a certeza de acesso a propriedade dos seus bens deixados, permitindo aos legitimados a investidura de sua posse e propriedade. 
Neste sentido, Maria Berenice Dias (2008, p. 24) afirma que "o próprio Estado tem interesse na manutenção da família, pois com isso se desonera do compromisso de garantir aos seus cidadãos o leque de direitos que lhes são assegurados na Constituição".

Desta maneira, se a própria família dispõe de meios para garantir a subsistência de seus membros, o Estado se vê dispensado de suas obrigações.

$\mathrm{O}$ direito à sucessão encontra-se consagrado no artigo 1.784 do Código Civil, estabelecendo que: '’aberta a sucessão, a herança transmite-se, desde logo, aos herdeiros legítimos e testamentário “. (BRASIL,2002)

A sucessão legitima é aquela em que o legislador traz a ordem de vocação hereditária, através da qual designa aqueles que serão chamados para suceder, ou seja, a lei indica os herdeiros da pessoa falecida.

Para Caio Mario da Silva Pereira, (2011, p. 67), denominase, então, sucessão legitima a que é deferida por determinação da lei. Quando ocorre o falecimento, em que, não deixa o testamento (intestado), diz-se também ab intestato.

Nesta situação, a transmissão se dá sem a manifestação de ultima vontade do de cujus, é a denominada sucessão ab intestato por não existir um testamento, trata-se da consagração do princípio da droit de saisine.

Para Pablo Stolze e Rodolfo Pamplona (2015, p.59), O princípio da "Saisine", pode ser definido como a regra fundamental do Direito sucessório, pela qual a morte opera a imediata transferência da herança aos seus sucessores legítimos e testamentários.

O Código Civil admite, além da sucessão legitima, a sucessão testamentaria em que a transmissão dos bens do de cujus será feita por expressa vontade antes do seu falecimento.

Segundo Flavio Tartuce, (2017, p. 1629) O testamento constitui um negócio jurídico unilateral, pois tem aperfeiçoamento com uma única manifestação de vontade: basta a vontade do declarante (testador) para que o negócio produza efeitos jurídicos.

O testamento é um negócio jurídico unilateral pois não beneficia ao autor da herança, é um negócio gratuito, não um negócio sinalagmatico em que precisa da contraprestação para aquisição dos bens ou direitos decorrentes do testamento.

Logo, a sucessão testamentaria é pouco utilizada no Brasil, devido a lei pátria ter contemplado, como regra a sucessão legitima, em que estabelece a ordem de vocação hereditária, em consequência disso muitos não fazem o testamento pela falta de patrimônio para dispor, até mesmo pelo medo da morte ou por acharem que a ordem de vocação hereditária prevista na lei é justa e correta.

Saliente-se, ainda, que a sucessão testamentaria, em geral é uma opção do sucedido, quando este não possui herdeiros necessários (art. 1.850 do Código Civil: "São herdeiros necessários os descendentes, os ascendentes e o cônjuge"), e é titular de um patrimônio considerável. Assim, a fim de beneficiar pessoas com quem tem ligação de consanguinidade distante, ou mesmo, com pessoas sem esta condição realiza testamento. (DINIZ, 2014)

Nesses casos o testador poderá dispor da totalidade de seus bens, por não possuir herdeiros necessários, caso contrário, deverá respeitar a legítima e não poderá dispor de mais da metade de seus bens no testamento ou em doação.

Uma outra forma do testador dispor de seu patrimônio é através de legado, que ocorrerá a título singular, pois o herdeiro sempre será um sucessor a título universal, ou seja, a universalidade do herdeiro é o patrimônio.

Para Silvio Venosa, (2007) O legado é uma deixa testamentária determinada dentro do acervo transmitido pelo autor da herança: um anel ou as joias da herança; um terreno ou um número determinado de lotes; ou as ações de companhias.

Para esse doutrinador legado é um bem determinado, ou vários bens determinados, especificados no monte hereditário. O legatário sucede a título singular, em semelhança ao que ocorre na sucessão singular entre vivos.

Entende-se, portanto, o legado, no ordenamento jurídico brasileiro como a atribuição de certos bens a outrem por meio do testamento a título singular.

Giselda Hironaka, (2007) afirma que o legado só poderá ser feito através do testamento, razão pela qual, tudo que for economicamente apreciável e que possa ser objeto de um negócio jurídico pode ser objeto de um legado.

Desde a abertura da sucessão o que ocorre com a causa mortis, produz desde logo os seus efeitos, pertencente ao legatário a coisa certa, existente no acervo.

Para Diniz, (2014) o legado é, portanto, a disposição testamentaria a título singular, pela qual o testador deixa a pessoa estranha ou não à sucessão legítima um ou mais bens individualizados ou certa quantia em dinheiro.

O Código Civil descreve em seu art. 1.923 "Desde a abertura da sucessão, pertence ao legatário a coisa certa, existente no acervo, salvo se o legado estiver sob condição suspensiva". (BRASIL, 2002)

Logo, o legatário não ingressa na posse da coisa quando ocorre a morte do testador, não obstante, desde a abertura da sucessão, a coisa legada já pertence ao legatário.

No que se refere aos "ativos digitais", denote-se que são aqueles também chamados de bens digitais, incluindo, portanto, nesta categoria fotos, textos, livros, bitcoins, websites, contas em redes sociais, dentre outros, todos armazenados de forma digital, ou seja, não só aqueles que tem valor pecuniário, mas também aqueles de valor sentimental.

Com base na política de dados de uso encontrada na plataforma do Facebook foi oferecido algumas soluções mesmo ainda a legislação atual brasileira não dispondo sobre o assunto. (FACEBOOK, 2019). Contudo, analisando os termos de serviço do Twitter, Gmail e Hotmail, não foram encontrados em seu termo de uso sobre a possiblidade de transmissibilidade desses conteúdos digitais caso o titular dessa conta venha a falecer. O Instagram no gerenciamento da sua 
conta permite que um perfil seja excluído mediante solicitação e apresentação de documentos que comprovem o óbito, sendo que o Facebook e o Instagram, ainda disponibilizam a opção de tornar o perfil um memorial. (FACEBOOK, 2019)

De acordo com termos de uso do Facebook tem a política de apresentar dois opções para a família que perdeu um ente querido e não sabe o que fazer com o perfil inativo. A primeira delas é transformar a página em um memorial, onde o acesso é restrito a amigos confirmados pelo de cujus e mantido apenas o conteúdo principal. A segunda opção é apagar todos os dados do usuário, excluindo a conta. (FACEBOOK, 2019)

No primeiro caso pode designar uma pessoa chamada "contato herdeiro" que irá administrar a conta caso ela seja transformada em memorial. Somente a pessoa designada como contato herdeiro ou a pessoa que esteja identificado no testamento válido ou documento semelhante que expresse consentimento claro para divulgar seu conteúdo em caso de morte. (FACEBOOK, 2019)

Em seu mecanismo de configurações o Facebook permite ao usuário o contato herdeiro, ou seja, a pessoa indicada pelo titular do acervo digital que escolherá para cuidar da sua conta quando ela for transformada em memorial, caso esta opção não seja realizada pelo titular do acervo digital a conta será excluída permanentemente pelo Facebook. (FACEBOOK, 2019)

Existem dois caminhos para a guarda do acervo digital, arquivado no Facebook, a desativação ou a exclusão permanentemente a conta. Se a pessoa possuía uma conta no Facebook, mas ela está atualmente desativada, é possível reativá-la. Para isso, basta entrar novamente no Facebook ou usar a conta para entrar em outro local. (FACEBOOK, 2019)

Registre-se que no caso de exclusão permanente da conta pelo titular, terceiros não possuem mais acesso ao perfil, no entanto, o titular da conta poderá solicitar a reativação da conta, utilizando o mesmo login de acesso da conta excluída, permanecendo arquivados no servidor do Facebook algumas informações, como mensagens enviadas a amigos, pelo prazo de até noventa dias. Ademais, as mensagens enviadas anteriormente à solicitação da exclusão da conta, restarão arquivadas e visíveis, para os amigos do titular da conta. (FACEBOOK, 2019)

Note-se que os Termos de Serviços do Facebook, informa que após a reativação da conta, em caso de desativação, garantem, posteriormente, ao titular da conta, a qualquer tempo, acesso a todas as informações da conta, bem como, a utilização da ferramenta de download de todas as informações. Contrariamente, na hipótese de solicitação de exclusão da conta pelo seu titular, após encerrado o prazo de noventa dias, não será mais possível acesso às informações armazenadas no Facebook. (FACEBOOK, 2019)

Vale salientar que todo o pedido de exclusão da conta pelo seu titular, pode ser cancelado, se este pedido não datar de mais de trinta dias. Após o transcurso prazo de trinta dias, contados da data do pedido de exclusão da conta, o titular da conta não terá mais acesso às informações, não sendo possível, portanto, a este recuperá-las. (FACEBOOK, 2019)

Algumas informações, como mensagens enviadas a amigos, poderão continuar visíveis para eles depois da exclusão da conta caso ocorra há menos de trinta dias. Depois desse prazo, a conta e todas as informações serão excluídas permanentemente. Não sendo possível recuperá-las. (FACEBOOK, 2019)

Importante salientar que o Facebook poderá levar até noventa dias, contados do pedido de exclusão da conta, para que o acervo digital armazenado no Facebook seja excluído. Todavia, após o pedido de exclusão da conta todo o acervo digital estará inacessível aos demais usuários do Facebook. (FACEBOOK, 2019)

Curioso notar que os Termos de Serviços do Facebook, informam que o acervo digital da conta do titular que solicitou a exclusão permaneça armazenado em backup no servidor desta plataforma de comunicação e interação social, após os noventa dias, referidos acima, contados da data do pedido de exclusão da conta pelo seu titular. (FACEBOOK, 2019)

Outrossim, anote-se que o Facebook se reserva ao direito de armazenar o acervo digital, mesmo de conta excluída, a fim de assegurar "questões como problemas legais, violações de termos ou esforços de prevenção de danos". (FACEBOOK, 2019)

Reforce-se que o ato de exclusão da conta a pedido do usuário, impede o mesmo de solicitar a sua reativação, bem como, de acesso às fotos, publicações, vídeos e todo o conteúdo que o titular adicionou serão excluídos permanentemente. (FACEBOOK, 2019)

Outrossim, novas contas abertas em outras plataformas de comunicação e interação social, a exemplo do Spotify ou Pinterest, utilizando o login do Facebook serão também excluídas. Assim, o acesso ao acervo digital armazenado nestas novas contas, deve ser solicitado aos administradores destas plataformas. (FACEBOOK, 2019)

Logo, existem dois caminhos a serem alcançados para ter acesso as contas do Facebook de falecidos: transformar em memorial ou solicitar a remoção da conta. No caso de memorial, há proteção contra acesso de terceiros, tornando um local onde apenas os familiares e amigos podem ter acesso, não sendo permitido nenhum login, para que não ocorra o acesso por um desconhecido e ele exiba informações no espaço público. (FACEBOOK, 2019)

Esse contato poderá responder às novas solicitações de amizade, atualizar imagem de perfil e foto de capa. Não poderá, no entanto, fazer login na conta, remover conteúdo postado anteriormente e nem acessar mensagens enviadas. Caso haja preferência para a remoção de uma conta, basta acessar as configurações da conta e selecionar a aba "contato herdeiro" e informar os dados solicitados. Não há permissão para acesso à conta de outra pessoa em razão de tal fato violar a política do Facebook. (FACEBOOK, 2019) 
O Instagram permite que as contas de usuários dos falecidos sejam apagadas ou transformadas em memorial. Qualquer pessoa que tenha conhecimento da morte de alguém pode denunciar para que a rede social a transforme a conta em memorial. (INSTAGRAM, 2018)

No caso do Instagram os termos de utilização regulam o tema de forma diversa, já que o perfil é transformado em uma espécie de homenagem póstuma. Destaque-se que na rede social do Instagram não há permissão para o acesso por parte de nenhuma outra pessoa, nem que o perfil sofra qualquer tipo de alteração, ou seja, são mantidas inalteradas as curtidas, seguidores, marcações, publicações e comentários. E, somente, parentes diretos conseguem solicitar a exclusão da conta. (INSTAGRAM, 2018)

Por isso, a rede social do Instagram solicita documentos que comprovem a relação de parentesco, como a certidão de nascimento ou a certidão de óbito do usuário falecido ou a comprovação de autoridade, de acordo com a lei local, de que é o representante legal dessa pessoa ou de seu espólio. (INSTAGRAM, 2018)

Algumas redes sociais e serviços online ainda não dispõe em seu termo da possibilidade do utilizador redigir uma declaração antecipada de última vontade sobre a sucessão de tais bens digitais. Neste sentido, tais redes de interação social, multiplicam o risco de perda do acervo digital do sucedido, já que não permite a opção de transferência para um contato herdeiro, impedindo assim, que o titular de contas nestas redes sociais, façam uso da sucessão testamentária, via declaração de última vontade antecipada, por meio do legado.

A exemplo dos serviços ofertados aos utilizadores da rede pelo Google, YouTube, Gmail e Hotmail, que não facultam a possibilidade da transferência do acervo digital, via contato herdeiro. Destaque-se que os termos de utilização dos serviços destas grandes empresas prestadoras de serviços na internet, apenas facultam o acesso ao acervo digital, em casos de decisão judicial.

Por isso, é que recentemente, alguns casos foram trazidos ao judiciário brasileiro, por familiares de sucedidos com acervos digitais arquivados em redes sociais e aplicações de comunicação na internet, como as referidas acima, com o propósito de obterem acesso a tais bens, junto aos administradores destas empresas, prestadores de serviços na internet.

Deste modo, na hipótese de impedimento do sucedido realizar antecipadamente a sua declaração de última vontade sobre o acervo digital arquivado nas plataformas de comunicação e interação social, notoriamente está-se diante de uma grave violação do direito fundamental à sucessão.

Persistindo esta violação, o sucedido fica impedido de conferir acesso ao seu acervo digital, correndo o risco deste se perder, pois como já visto, algumas destas plataformas de comunicação e interação social, após a morte do utilizador, cancelam a conta.

Ademais, registre-se que a violação incide tanto na esfera jurídica do sucedido, como de seus herdeiros, que se vêm impossibilitados de colacionar o acervo digital, com profundo teor familiar e emocional nele contido.

\subsection{Ordenamento Jurídico Brasileiro e a Herança Digital}

O Código Civil brasileiro não versa sobre à herança digital, nem dos bens armazenados virtualmente. Assim, estes bens advindos da sucessão serão interpretados à luz do diploma civil brasileiro, que garante aos familiares mais próximos do falecido, direito à sucessão, consoante os artigos 1784, 1.786, 1.788, 1.829, 1.845, 1.846 e 1.857 do Código Civil.

Note-se que a legislação pátria ainda não dispôs sobre a sucessão do patrimônio digital, regulando especialmente a declaração antecipada de última vontade sobre o acervo digital arquivado em plataformas de comunicação e interação social.

Destaque-se, que também a nova Lei de Proteção de Dados Pessoais (Lei 13.709/2018) - que entra em vigor em 2020 para alterar o Marco Civil da Internet (Lei 12.965/2014) - regula sobre a matéria.

Neste sentido, sem a devida e necessária previsão legal, não há respaldo para a proteção do direito sucessório do acervo digital deixado pelo sucedido nas plataformas de comunicação e interação social.

Registre-se, no entanto, que há um projeto de Lei de n. ${ }^{\circ}$ 4099/2012, de autoria do Deputado Jorginho Mello, que altera o Código Civil, propondo a modificação do art. 1.788 do Código Civil brasileiro, para dispor especialmente sobre a sucessão dos bens e contas digitais do autor da herança.

O art. 1788 do CC de 2002 passaria a ter a seguinte redação: “[...] Parágrafo único. Serão transmitidos aos herdeiros todos os conteúdos de contas ou arquivos digitais de titularidade do autor da herança".

Esta alteração inclusive obrigaria às empresas prestadoras de serviços na internet a criarem funcionalidades tecnológicas que permitissem aos herdeiros acesso ao acervo digital, automaticamente ao falecimento do titular de conta em plataformas de comunicação e interação social.

Sem embargo, o problema a ser enfrentado pelo Direito, nessa sociedade da informação e de risco, notadamente em face das relações sociais que foram também digitalizadas, é regular a sucessão do patrimônio digital.

A Lei n. ${ }^{\circ}$ 12.965/14 conhecida como Marco Civil da Internet rege os direitos do uso da internet no Brasil, estabelecendo como base principiológica a respeito de temas como a neutralidade da rede, liberdade de expressão e privacidade. Logo, não fala em direito sucessório do acervo digital do de cujus, dispõem, portanto, sobre os direitos de privacidade do usuário e regula o tempo em que os registros devem permanecer armazenados por parte do servidor.

De acordo com artigo 13, da lei 12.965/2014:

Art. 13. Na provisão de conexão à internet, cabe ao administrador de sistema autônomo respectivo o dever de manter os registros de conexão, sob sigilo, em ambiente controlado e de segurança, pelo prazo de 1 (um) ano, nos termos do regulamento. (BRASIL, 2014) 
Com base nesse artigo o legislador garantiu o direito de privacidade do usuário e determinou o armazenamento por parte do servidor pelo prazo de um ano obedecendo o sigilo.

Mesmo com a criação da lei, ainda há questões que não foram abordadas, no que tange a sucessão dos bens post morten, pois algumas redes sociais não têm implementado em seus contratos o direito da pessoa que não conseguiu em vida explanar sua vontade, permitindo nesses casos que seus familiares decidam o que irão fazer com os seus acervos digitais. Por mais que essas leis tragam em seu bojo pontos relevantes não conseguiram abranger pontos relevantes da herança digital.

Com o crescimento das informações armazenadas digitalmente, a probabilidade do judiciário ser chamado para resolver casos sobre o direito sucessório ao acervo digital, aumentará exponencialmente, demandando a emissão de ordens judiciais e alvarás para simplesmente garantir aos familiares do sucedido acesso ao acervo digital, que em geral reveste-se de forte caráter emocional.

No ano de 2013 chegou ao judiciário brasileiro, a mãe da jornalista Juliana Ribeiro Campos, que solicitou diversas e reiteradas vezes a exclusão do perfil da filha, mas não obteve êxito com os administradores dos serviços da plataforma de comunicação e interação social do Facebook no Brasil.

A decisão judicial determinou a exclusão do perfil, pois a autora já se encontrava em sofrimento pela perda prematura da única filha. De acordo com a liminar concedida:

O perigo na demora está consubstanciado no direito da personalidade, tanto da pessoa morta quanto da mãe (art. 12, parágrafo único, do $\mathrm{CC}$ ), sanando o sofrimento decorrente da transformação do perfil em "muro de lamentações", o que ataca diretamente o direito à dignidade da pessoa humana da genitora, que além do enorme sofrimento decorrente da perda prematura de sua única filha, ainda tem que conviver com pessoas que cultivam a morte e o sofrimento. (TJ-MS, 2013)

O Tribunal de Justiça do Mato Grosso do Sul deferiu o pedido, entendendo que a mãe possui legitimidade para solicitar a exclusão do perfil da filha. (TJ-MS, 000100727.2013.8.12.0110)

Frise-se que neste caso, o Facebook ainda não disponibilizava o serviço de contato herdeiro, funcionalidade esta que apenas fora disponibilizada aos usuários desta plataforma de comunicação e interação social no ano de 2015. (TECHTUDO, 2015)

Contudo, pode ocorrer que mesmo o usuário ciente do serviço de contato herdeiro, não opte por esse serviço. Deste modo, indaga-se da possibilidade de transferência do acervo digital deixado pelo falecido, na hipótese deste em vida não haver realizado a declaração antecipada a favor da sucessão de tais bens aos herdeiros.

Obviamente, que as especificidades da situação em concreto nortearão a decisão do judiciário nesta hipótese, pois se deve levar em consideração o nível de conhecimento técnico do falecido sobre as funcionalidades da plataforma digital, bem como, diversos outros fatores que possam oferecer pistas ao julgador sobre a vontade deste em transferir o seu acervo digital, após a sua morte aos sucessores.

No entanto, em abstrato, a análise desta faculdade ofertada ao falecido parece demonstrar que a não opção pelo serviço do contato herdeiro, antecipa a vontade deste de não facultar acesso ao acervo digital aos seus sucessores, desejando assim manter intacta a sua privacidade e intimidade.

Logo, por se tratar de direitos essências e personalíssimo, parece razoável entender pela não transmissão aos herdeiros o acervo digital do falecido. Desta forma, obriga-se os provedores de aplicações da internet a apagar todo o acervo digital do falecido, mantendo intacta a sua privacidade e intimidade.

Por outo lado, em outro processo o entendimento do magistrado foi de forma diversa, decidiu na ideia de que a herança digital do falecido possui natureza personalíssima e consequentemente o acesso ao acervo digital do titular da conta do falecido não deve ser transmitido aos seus herdeiros. (TJ-MG,0023375-92.2017.8.13.0520)

Outro caso, foi julgado pelo Tribunal de Justiça de Minas de Gerais. Neste, o juiz, entendeu ser improcedente o pedido da autora em obter o acesso aos dados pessoais da filha falecida na internet. $\mathrm{O}$ magistrado fundamentou a sua decisão com argumento no art. $5^{\circ}$, inciso XII, da Constituição Federal, que trata sobre o sigilo da correspondência e das comunicações telegráficas, de dados e das comunicações telefônicas. (TJMG,0023375-92.2017.8.13.0520)

Sentenciou, então, o magistrado:

Dada essa digressão, tenho que o pedido da autora não é legítimo, pois a intimidade de outrem, inclusive da falecida Helena, não pode ser invadida para satisfação pessoal. A falecida não está mais entre nós para manifestar sua opinião, motivo pela qual a sua intimidade deve ser preservada. (TJMG, 2017)

Neste sentido, na ausência de legislação específica que verse sobre o tema, bem como, jurisprudência pacífica sobre a abusividade de determinados condições imposta por provedores de aplicações da internet, tais como contratos que regem a maioria das relações estabelecidas online, e/ou o termo de uso de serviços de armazenamento de dados, e-mails e redes sociais que reconheça a propriedade do usuário sobre conteúdo por ele armazenado, a possibilidade de transmissão deste acervo digital do sucedido aos seus familiares, resta nebulosa.

Aponte-se que falar sobre herança digital, implica em definir o que será feito com o acervo digital após a morte do titular de contas em plataformas digitais de comunicação e interação social. Como salientado, anteriormente, no Brasil, não há legislação que trate da herança digital. Assim, a grande preocupação é como definir um marco regulatório mínimo de atuação das empresas prestadores de serviços na internet, ou seja, dos provedores de aplicações na internet, sejam eles provedores de conteúdo, de correio eletrônico e/ou de hospedagem. 
Sem embargo, a insegurança jurídica é grande para a defesa do direito fundamental à sucessão aberta, pois que, resta nas mãos dos provedores de aplicações na internet, a disponibilização de funcionalidades informáticas, que garantam aos titulares de contas a antecipação da declaração de última vontade.

Registre-se que hoje são três os projetos de lei tramitando na Câmara dos Deputados sobre a herança digital. O Projeto de Lei n. ${ }^{\circ}$ 7.742/2017 propõe a inserção de um artigo ao Marco Civil da Internet que fala sobre a exclusão das contas online do usuário falecido caso não tenha testado, permitindo em último caso que os familiares possam ter acesso a tais contas. $\mathrm{O}$ art. 10-A, portanto, teria a seguinte redação:

Art. 10-A. Os provedores de aplicações de internet devem excluir as respectivas contas de usuários brasileiros mortos imediatamente após a comprovação do óbito.

$\S 1^{\circ} \mathrm{A}$ exclusão dependerá de requerimento aos provedores de aplicações de internet, em formulário próprio, do cônjuge, companheiro ou parente, maior de idade, obedecida a linha sucessória, reta ou colateral, até o segundo grau inclusive. $\S 2^{\circ}$ Mesmo após a exclusão das contas, devem os provedores de aplicações de internet manter armazenados os dados e registros dessas contas pelo prazo de 1 (um) ano, a partir da data do óbito, ressalvado requerimento cautelar da autoridade policial ou do Ministério Público de prorrogação, por igual período, da guarda de tais dados e registros.

$\S 3^{\circ}$ As contas em aplicações de internet poderão ser mantidas mesmo após a comprovação do óbito do seu titular, sempre que essa opção for possibilitada pelo respectivo provedor e caso o cônjuge, companheiro ou parente do morto indicados no caput deste artigo formule requerimento nesse sentido, no prazo de um ano a partir do óbito, devendo ser bloqueado o seu gerenciamento por qualquer pessoa, exceto se o usuário morto tiver deixado autorização expressa indicando quem deva gerenciá-la. (BRASIL,2017)

Tramita também outro Projeto de Lei n. ${ }^{\circ}$ 8.562/2017 que pretende incluir três novos artigos ao Código Civil de forma a inserir o conceito de herança digital, de fato, no ordenamento jurídico, apresentando um rol exemplificativo dos bens que podem compor o acervo.

Assim, o art. 1.797-A deveria prever um rol exemplificativo dos bens que podem compor o acervo. $\mathrm{O}$ texto do dispositivo teria essa proposta:

Art. 1.797-A. A herança digital defere-se como o conteúdo intangível do falecido, tudo o que é possível guardar ou acumular em espaço virtual, nas condições seguintes: I - senhas; II - redes sociais; III - contas da Internet; IV - qualquer bem e serviço virtual e digital de titularidade do falecido. (BRASIL,2017)

Em sequência, o art. 1.797-B prevê a real possibilidade da chamada herança digital. Diria o dispositivo:

Art. 1.797-B. Se o falecido, tendo capacidade para testar, não o tiver feito, a herança será transmitida aos herdeiros legítimos. (BRASIL,2017)

Por fim, o art. 1.797-C pretende sugerir as opções deixadas ao herdeiro, quais sejam:

Art. 1.797-C. Cabe ao herdeiro:I - definir o destino das contas do falecido; a) transformá-las em memorial, deixando o acesso restrito a amigos confirmados e mantendo apenas o conteúdo principal ou;

b) apagar todos os dados do usuário ou;

c) remover a conta do antigo usuário. (BRASIL,2017)

Note-se que o conceito de herança digital ainda é pouco difundido, apesar de não ser incomum a ideia de preservar a propriedade imaterial, ou seja, é possível que acervos de músicas, filmes, livros e documentos armazenados em nuvem, valendo-se de programas como iCloud, Dropbpox e Google Docs, sejam deixados a herdeiros, isto é, havendo um bem digital que interesse aos herdeiros, estes têm direito a herdálos. Logo, a herança digital pode ser definida como o conjunto patrimonial ou extrapatrimonial arquivado em formato digital, do indivíduo, garantindo assim, a transferência aos herdeiros destes bens, bem como, dos direitos e obrigações incidentes sobre os mesmos.

Claro está que a realidade da atual sociedade da informação, estabelece uma nova estratificação de relacionamentos digitais, especialmente, em virtude da grande exposição diária de cada indivíduo na Internet, com postagem de fotografias, imagens, vídeos, armazenamento de conteúdo em nuvem.

Neste sentido, o que o direito deve considerar é não somente a grande soma de bens de natureza patrimonial envolvida, mas também os bens de natureza essencialmente pessoal, de grande valor sentimental agregado. A exemplo das fotografias, filmagens de nascimentos, casamentos e outros momentos, armazenadas em dispositivos informáticos, que tanto envolvem direitos pessoais do falecido, como das pessoas amigas e familiares que com ele conviveu e deseja ter acesso à essa memória afetiva.

Assim, cabe à ciência jurídica sopesar todas estas faculdades patrimoniais e pessoais, tanto do falecido como dos seus sucessores, de modo a ponderar a melhor solução para o acervo digital deixado pelo falecido, evitando que este se perca, ou mesmo que venha a ser utilizado de forma inadequada violando não somente a privacidade e intimidade do falecido, como de seus entes queridos.

Observe-se que em sua maioria as propostas de alteração da legislação no Brasil, orientam-se no sentido de proteger a privacidade e a intimidade do falecido que não realizou a declaração de última vontade, impedindo, portanto, a transferência do acervo digital para os seus sucessores.

Note-se que este tema é complexo, pois não somente envolve o debate sobre a privacidade e a intimidade do falecido. Deve ser levado em consideração na discussão os direitos dos herdeiros à sucessão aberta, a proteção dos bens de natureza patrimonial, bem como, de natureza pessoal, que revelam grande valor sentimental, com reflexos inclusive possíveis na esfera de terceiros.

As contas transformadas em memorial são um local em que amigos e familiares podem se reunir para compartilhar lembranças após o falecimento de uma pessoa. A transformação de uma conta em memorial também ajuda a protegê-la, 
impedindo que as pessoas entrem nela. (FACEBOOK, 2019)

De acordo com a política do Facebook, uma conta é transformada em memorial quando algum familiar ou amigo próximo da pessoa falecida avisa sobre o ocorrido.

Transformar uma conta em memorial é uma grande decisão, caso não seja um familiar ou amigo próximo da pessoa que faleceu, é recomendado que entre em contato com a família antes de solicitar a transformação da conta em memorial. (FACEBOOK,2019)

As contas transformadas em memorial têm a expressão "Em memória de" que será exibida ao lado do nome da pessoa no perfil, dependendo das configurações de privacidade da conta, os amigos poderão compartilhar lembranças na linha do tempo transformada em memorial, o conteúdo que a pessoa compartilhou (por exemplo, fotos e publicações) permanecerá no Facebook e ficará visível para o público com o qual foi compartilhado. (FACEBOOK,2019)

Os perfis transformados em memorial não serão exibidos em espaços públicos, como nas sugestões de pessoas que tenha amigos em comum, em lembretes de aniversário ou em anúncios, e por fim ninguém poderá entrar em uma conta transformada em memorial. (FACEBOOK,2019)

A conta continuará visível no Facebook, mas a única pessoa que pode gerenciar uma conta transformada em memorial é o contato herdeiro selecionado pelo titular. (FACEBOOK,2019)

Em muitos casos, quando uma conta é transformada em memorial, não é possível remover o conteúdo dessa conta. Se a pessoa adicionar um contato herdeiro à sua conta, esse contato poderá fazer ações do tipo: alterar a imagem do perfil e a foto da capa da pessoa, escrever uma publicação fixada na Linha do tempo e responder a novas solicitações de amizade. (FACEBOOK,2019)

Uma vez a conta transformada em memorial, não será possível adicionar um contato de legado a uma conta que já foi transformada em memorial, pois o contato herdeiro é escolhido pelo titular da conta, e não será administrada ativamente por ninguém após a solicitação de transformação.

Entende-se que mesmo que os familiares tenham a senha do perfil não será fornecido as informações de login da conta, caso contrário violaria as políticas do Facebook. O Facebook ciente do falecimento transformará desde logo a conta no memorial. (FACEBOOK,2019)

Outrossim, no que tange aos diversos projetos de lei sobre herança digital, registre-se que os mesmos trazem como disciplina a obrigatoriedade de identificação de pessoa específica para administrar o perfil nas redes sociais do falecido. Estes projetos, também, avançam no sentido de determinar que na hipótese de o falecido não realizar esta declaração de última vontade, identificando o sujeito que irá administrar o seu acervo digital, ocorrerá a transformação do perfil do falecido na rede social em memorial.

Deste modo, uma vez transformado o perfil do falecido na rede social em memorial, qualquer um estará impedido de acessar o acervo digital deste, inclusive os seus familiares, mesmo que de posse dos dados de login e senha se acesso.

Sem sombra de dúvidas a proteção ao utilizador da rede no Brasil, nesta matéria é bastante penosa, já que sob a égide de diplomas inadequados para as especificidades que o avanço tecnológico impõe à estas novas relações estabelecidas com a digitalização e a virtualização da realidade analógica.

Ademais, denote-se que este novo contexto tecnológico, estabelece relações que desconhece o que está "online" ou "offline", já que permite interações simultâneas, múltiplas e diversas das relações sociais.

Deste modo, a tutela do acervo digital é um novo paradigma que se apresenta ao direito, para o qual as soluções pensadas ainda estão longe de pacificar essa multitude de possibilidades e de interações.

\section{Conclusão}

A sociedade ao longo do tempo passou e continua passando por diversas mudanças significativas, que mudaram completamente a vida das pessoas. Sem sombras de dúvidas a primeira delas foi a Revolução Industrial na Inglaterra do século XVIII trazendo novas formas de produção, resultado dos avanços de uma integração cada vez maior entre ciência, produção e tecnologia.

O descobrimento da robótica, a chegada do computador e da internet são alguns dos principais marcos da Terceira Revolução Industrial. Revolução essa conhecida como a Era da Informação ou Era Digital.

Contudo, a quarta Revolução Industrial é disruptiva, pois marcada pela união de tecnologias físicas, digitais e biológicas e tem o potencial de transformar vidas, revolucionando sistemas, viabilizando novas descobertas, encurtando distâncias e promovendo a interação entre as pessoas, independentemente do local onde elas estejam.

Hoje se experimenta ápice dessa revolução, pois o homem passa a ter acesso ao mundo através das suas mãos. As pessoas estão mais conectadas, cercadas por informação ao seu redor, bem como, mais esclarecidas sobre os seus direitos, já que titulares do acesso à uma gama de informações, permitindo assim novas descobertas e transformação de vidas.

Claramente, o avanço tecnológico tem levado a sociedade a gerar um acervo imenso de ativos e valores digitais, foise o tempo de acumular fotos em álbuns. Hoje, tudo pode ser desmaterializado, virtualizado, digitalizado, publicado em blogs, sites, e-mails e, especialmente, em redes sociais. Notadamente, essa mudança no comportamento humano é um sinal claro de que, cada vez mais, as lembranças deixam de ser tangíveis.

Com todas essas mudanças trazidas não há que se falar somente do patrimônio material, mas sim do patrimônio imaterial. Deste modo, o acervo digital pode ser compreendido como os de valor econômico que envolvem o acúmulo de materiais de autoria própria, como músicas, poemas, textos e fotos; bem como, como aqueles compreendidos de valor sentimental ou afetivo, a exemplo do bate papo, salvo em 
chat, das inúmeras conversas realizadas de forma online, da gestão das contas nas redes sociais, dos posts e das senhas de e-mails e outros aplicativos.

Tradicionalmente o direito não reservou espaço para tutela dessa nova categoria de bens, que sem sombra de dúvidas deve passar a compor o direito sucessório. Especialmente, em face destes conter valores sentimentais, e por refletirem a tutela à intimidade da pessoa.

Assim, é inegável a necessidade de tutela jurídica desta nova categoria de bens, que compõem na era digital a nova estrutura do patrimônio do indivíduo, compreendendo o acervo "offline" e "online".

Destarte, o ordenamento jurídico brasileiro precisa adaptar-se às necessidades demandadas por esse novo cenário. A legislação tradicional não se apresenta suficiente e capaz de atender as diversas interações surgidas e potencializadas pela

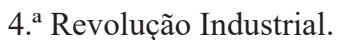

Sem embargo, é necessário conferir atenção aos efeitos e às consequências que os atos virtuais podem causar na vida real, pois o risco de violação ao direito e à proteção da privacidade da pessoa falecida, bem como, de seus herdeiros e terceiros é enorme. Especialmente, em razão da ausência de legislação adequada para resguardar e preservar a tutela dos bens que compõem o acervo digital do falecido.

Percebe-se, nitidamente, do estudo realizado, que algumas plataformas de comunicação e interação social, não disponibilizam que seus usuários exprimam sua vontade quanto a destinação dos bens que compõem o acervo digital destes, causando uma insegurança jurídica.

Registre-se também, conforme o pesquisado, que o embate jurídico causado pelo tema, põe em causa o direito à reserva da intimidade do falecido e o direito à sucessão aberta dos herdeiros do falecido de obterem acesso ao conjunto de bens digitais por este deixado.

É mister, ao direito sopesar os interesses em jogo, confrontando qual deve prevalecer sobre o outro, equilibrando e harmonizando o conflito entre as diversas categorias de direitos fundamentais que se apresentam ao tema.

Deste modo, até que se estabeleça um marco regulatório específico para cuidar da matéria, conclui-se que os herdeiros do falecido somente devem ter a garantia do direito à sucessão aberta tutelada, quando o falecido assim se manifestar.

Portanto, entende-se que o acesso indiscriminado aos sucessores do falecido do conjunto de bens que compõe o seu acervo digital, perpetua-se em violação à garantia fundamental de reserva à sua privacidade e intimidade.

Acresça-se, inclusive, que esta solução jurídica deve ser aplicada mesmo na hipótese de não manifestação de vontade por parte do falecido, quer esta opção seja ou não conhecida por este.

Por fim, este trabalho entende que os herdeiros do falecido só devem ter o direito de gerenciar o acervo digital quando o titular desses bens assim o declarar. Notadamente, o contexto atual do ordenamento jurídico brasileiro, demanda por uma posição mais conservadora, de proteção especial aos bens imateriais, com elevado cunho sentimental, resguardando-se a privacidade e a intimidade do falecido.

De mais a mais, o presente trabalho propõe diante dessa insegurança quanto à tutela do conjunto de bens que integram o acervo digital do falecido, que se estabeleça um marco regulatório adequado, em especial determinando a obrigatoriedade dos provedores de aplicação da internet a excluírem todo e qualquer dado pessoal do falecido, quando não houver declaração de última vontade deste para guarda ou mesmo transmissão do acervo digital aos seus herdeiros.

Evidentemente, esta proposta passa por alterar o art. 16 do Marco Civil da Internet, introduzindo nele mais dois incisos que estabeleça aos provedores de aplicação da internet a vedação da guarda do acervo digital do falecido, quando este não se manifestar expressamente de forma contrária, bem como, a obrigatoriedade de exclusão de todo e qualquer dado do falecido das plataformas de comunicação e interação social.

Aponte-se que esta proposta de alteração legislativa é apenas remediar a adequada solução jurídica para a matéria. Na verdade, o tratamento da matéria passa pela discussão em primeiro da adequada tutela desta nova realidade de bens surgidos, bem como, a previsão de um regime jurídico sucessório diferenciado para esta nova categoria de bens.

\section{Referências}

AMARAL, Francisco. Direito Civil Introdução. Rio de Janeiro: Renovar, 2008.

BARRETO, A.G.; NERY NETO, J.. Herança Digital. Direito \& TI - Debates Contemporâneo: Disponível em: <http:// direitoeti.com.br/site/wp-content/uploads/2016/03/BARRETOAlesandro-Gon\%C3\%A7alves-NERY-NETO-Jos\%C3\%A9Anchi\%C3\%AAta-Heran\%C3\%A7a-Digital.pdf>. Acesso em: 1 maio 2020.

BEVILAQUA. C. Teoria Geral do Direito Civil. Campinas: Red Livros, 2001.

BRASIL. Lei 12.965, de 23 de abril de 2014. Planalto. Legislação. Disponível em: <http://www.planalto.gov.br/ ccivil_03/ato2011-2014/2014/lei/112965.htm>. Acesso em: $27 / 10 / 201 \overline{9}$.

BRASIL, Lei 10.406, 10 de janeiro de 2002.Código civil. Diário Oficial da República Federativa do Brasil. Brasília, DF, 2002. Disponível em: http://www.planalto.gov.br/ccivil_03/Leis/2002/ L10406.htm Acessado em : 22 de abril. 2019

BRASIL. Lei $\mathrm{n}^{\circ} 13.709,23$ de abril de 2014. Estabelece princípios, garantias, direitos e deveres para o uso da internet no Brasil. Diário Oficial da República Federativa do Brasil. Brasília, DF, 2014. Disponível em: http://www.planalto.gov.br/ CCIVIL_03/_Ato2011-2014/2014/Lei/L12965.htm. Acessado em: 7 de abril. 2019

BRASIL. Projeto de Lei 4099/2012. Planalto. Legislação. Disponível em <http://www.câmara.gov.br/proposicoesWeb/ fichadetramitacao?idProposicao $=548678>$, acesso em 27.10.19.

BRASIL. Projeto de Lei 8562/2017.
Planalto. Legislação. Disponível em https:// w w w. camara.leg.br/proposicoes Web/prop mostrarintegra? codteor $=1596819 \&$ filename $=\mathrm{PL}+8562 / 2017$ 
BRASIL. Projeto de Lei 7742/2017. Planalto. Legislação. Disponível em https://www.camara.leg.br/proposicoesWeb/prop mostrarintegra? codteor $=1564285 \&$ filename $=\mathrm{PL}+7742 / 2017$

CAHALI, F.J. Direito das sucessões. São Paulo: Revista dos Tribunais, 2007.

DIAS, M.B. Manual das sucessões. São Paulo: Revista dos Tribunais, 2008.

DINIZ, M.H. Curso de direito civil brasileiro, volume 1: teoria geral do direito civil. São Paulo: Saraiva, 2011.

DINIZ, M.H. Curso de direito civil brasileiro, volume 6: direito das sucessões. São Paulo: Saraiva, 2014.

FARIAS, C.C. Curso de direito civil: parte geral e LINDB, volume 1. São Paulo: Atlas, 2015.

GAGLIANO, P. Stolze novo curso de direito civil, volume 7: direito das sucessões. São Paulo: Saraiva, 2015.

INSTAGRAM

https://www.techtudo.com.br/dicas-etutoriais/2018/03/instagram-o-que-fazer-com-o-perfil-de-umapessoa-falecida.ghtml. Acesso em: 27out. 2019

LIMA, I.R. Herança digital: direitos sucessórios de bens armazenados virtualmente. Brasília: UnB, 2013.

LARA, M.F. Herança digital. Porto Alegre: [s.e.], 2016.
PEREIRA, C.M.S. Instituições de direito civil. Rio de Janeiro: Forense, 2011.

SARLET, I.W. Dignidade da pessoa humana e direitos fundamentais na constituição Federal de 1988. Porto Alegre: Livraria do Advogado, 2009.

TARTUCE, F. Manual de direito civil: volume único. Rio de Janeiro: Forense, 2017.

TECHTUDO. O que é um contato herdeiro no Facebook? Recurso funciona pós-morte. 2015 Disponível em $<$ https://www. techtudo.com.br/noticias/noticia/2015/09/o-que-e-um-contatoherdeiro-no-facebook-recurso-funciona-pos-morte.html $>$ Acesso em: 30 out. 2019.

TRIBUNAL DE JUSTIÇA DO MATO GROSSO DO SUL. $1^{\text {a }}$ Vara do Juizado Especial Central. Processo 000100727.2013.8.12.0110. Juíza Vania de Paula Arantes. Em 19 março de 2013 .

TRIBUNAL DE JUSTIÇA DO MATO GROSSO. Comarca Pompeu - MG. Processo 0023375-92.2017.8.13.0520. Juiz Manoel Jorge de Matos júnior.

VENOSA, S.S. Direito Civil: parte geral. São Paulo: Atlas, 2003. VENOSA, S.S. Direito Civil: direito das sucessões. São Paulo: Atlas, 2003. 